\title{
The Analysis of Intercultural Adaptation Problems of Exchange Students in Foreign Language Universities*
}

\author{
Xuan Zhang \\ Guangdong University of Foreign Studies \\ Guangzhou, China
}

\author{
Qianyu Zhu \\ Guangdong University of Foreign Studies \\ Guangzhou, China
}

\begin{abstract}
With the great development of education internationalization, the number of exchange projects in universities has increased sharply in China. Meanwhile, more and more problems lying in educational management of exchange students in universities have emerged, which is mainly suggested in the aspects of interpersonal communication, values education and safety education. Foreign language universities can improve the intercultural adaptation ability of exchange students from the aspects of intercultural communicational education, values education and safety education.
\end{abstract}

Keywords-exchange students; Intercultural adaptation; safety education

\section{INTRODUCTION}

As the promotion of economic globalization and "the Belt and Road" initiatives, domestic universities attach more importance to international communication of higher education, especially for foreign language universities with more distinctive features of internationalization. In this kind of university, exchanging and studying abroad is even arranged in the education plan of some majors, which highlights the serious intercultural adaptation problems of exchange students. At present, the theoretical research regarding exchange students is comparatively limited, most of which mainly analyze the influence on the educational management of exchange students from the perspectives of different regions or different factors. According to practical experiences, universities set different standards foreducational management of exchange students and lack regulation. The problems regarding to intercultural adaptation of exchange students have also exposed the deficiencies in the educational management of university students, which requires us to put forward more useful advice on the basis of current situation and reasons to promote international communication of universities.

*The project supported Distinguished Young Talents Program of Educational Commission of Guangdong, China (Grant No. 2015WQNCX022) and Guangzhou Youth Program of Philosophy and Social Sciences for Developing the Thirteenth Five-year Plan Period (Grant No.2017GZQN30)

\section{THE EXISTING PROBLEMS IN INTERCULTURAL ADAPTATION OF EXCHANGE STUDENTS IN FOREIGN LANGUAGE UNIVERSITIES}

\section{A. Serious Intercultural and Interpersonal Problems}

A relevant research shows that a majority of exchange students participating in Sino-foreign education programmes can well adapt to the life abroad. According to five dimensional analysis of social culturaladaptation, the most difficult part of adapting is interpersonal communication. In other words, Chinese university students so far have not cultivated strong intercultural exchange awareness and language ability. Due to shallow understanding of intercultural knowledge, exchange students might not adapt to the social culture of other countries as easily as it was expected. Apart from adaptation problems related to personal mentality, studying, values and language barriers, they tend to expose more weaknesses in interpersonal communication with local people. Their expectation gap on intercultural communication as well as insufficient knowledge and ability leads to confusion during communication with professors and students from other countries. This situation also reflects that domestic universities have not paid enough attention to intercultural communication ability and its training, which is not conducive for exchange students to study and live abroad.

\section{B. Conflicts over Intercultural Values}

The education before going abroad for exchange students is usually fulfilled by lectures involving all students, which is not efficient enough to solve problems and not educating students according to the their personal situation. The education of patriotism, core socialist values and world outlook, view on life and values, has not been rooted in their minds. University students are not so experienced that they do not have deep understanding of the complicated matters in society. Lack of political experiences and social practice, exchange students are likely to get confused when faced with the shock caused by different social systems and cultures.

\section{Potential Risks of Intercultural Communication}

The interview records of exchange students showed that most of them had experienced safety incidents (either serious or not) during their stay abroad. Besides, most of them did 
not know how to deal with those incidents. Before the students go abroad, a majority of students only receive some conventional lecture-teaching education, which is just a formality and lack of systematization. At the same time, the students are not familiar with laws, regulations and social environment of other countries, and always worshiping everything abroad so that they do not pay much attention to their own property and local security condition, which may easily cause safety incidents such as property loss and so on.

\section{THE REASONS FOR INTERCULTURAL ADAPTATION} PROBLEMS OF EXCHANGE STUDENTS IN FOREIGN LANGUAGE UNIVERSITIES

\section{A. "Inadaptability" of Intercultural Communication Caused by the Lack of Intercultural Education Training}

Exchange students tend to have great expectation on the education, culture, life style and social system of other countries, hoping to form deeper understanding of them by studying abroad. Nevertheless, they might undervalue the cultural differences caused by various cultural characteristics, which reflects that the intercultural exchange awareness should be raised so that the students' adaptability to cultural shock can be essentially aroused. Meanwhile, language barrier is also a stumbling block for exchange students to live and study abroad. Some students practice more on writing and reading instead of listening and speaking when learning language, thus it needs certain time for them to use foreign language adapting the life abroad. Besides English, exchange students are also faced with communication difficulties caused by dialects or second languages. With poor master of these languages, the students' adaptability decreases. At last, domestic universities offer inadequate cultural knowledge courses specially designed for exchange students and just provides short-term training before their studying abroad, resulting in the deficiency of learning language, politics, economy, society and culture of the target country as well as intercultural communicational barrier which is caused by cultural differences.

\section{B. "Misunderstanding” of Intercultural Values Caused by Shallow Pre-judgment of Culture Differences}

Because of distinct characteristics of students, they will gradually form various impressions on local people when they are studying abroad because of their different personal experiences. Influenced by different political background, social system, religion and culture of each country abroad, exchange students are more likely to be influenced by different kinds of thoughts and feel confused about different values. From the perspective of inner factor, exchange students have not shaped profound comprehension on cultural differences and had enough knowledge on potential problems and difficulties during intercultural communication. The life goal and values of a majority of university students vary, and university students tend to fail to make right judgment and deal with the difficulties. From the perspective of outer factor, while exchange students are learning philosophy of education, professional knowledge and advanced technology in other countries, they will also be influenced by different cultures abroad, resulting in certain effect on their values caused by different ideology and life styles. When there are conflicts between original value and new value learned abroad, students may have no idea what to do. Therefore, exchange students need to strengthen education of patriotism and foster stronger confidence in the path, theory, system and culture.

\section{C. "Improvements" of Safety Consciousness Remaining to Be Done Because of Superficial Safety Education}

Many aspects could be involved when it comes to the safety problems of exchange students. But basically it can be concluded in two points: life and property security. Most of safety education coursesin university is in the form of lectures or group discussion before going abroad, reminding exchange students to learn more about target country's laws and regulations, traffic rules, medical insurance and so on. However, exchange students just learn them at superficial level instead of further understanding according to personal situation, making them not know how to deal with unexpectedproblems. Combining various factors and analysis, several reasons are found below. Firstly, exchange students lack safety and self-protection consciousness. Since reform and opening up policy has been implemented for 40 years, China has not only achieved sustained and sound economic development, but also achieved enormous progress on improving social security and living standards of citizens. In other words, China has become one of the safest countries in the world. Exchange students tend to carry this sense of security when studying abroad, leading to the lack of safety and self-protection consciousness during their living and studying in other counties. Secondly, the form and content of safety education in domestic university is not varied and profound enough. Most of exchange students have received safety education, but basically the education is in short period and not systematic enough, failing to help exchange students adapt to local environment and deal with safety problems when studying abroad, which causes property loss and personal safety problems. At last, the cultural differences keep exchange students away from local culture. Exchange students are not familiar with local culture and customs where they are living and studying, making conflicts and safety problems emerging easily. The most serious problem is "whether the private space is invaded or not" caused by differences between eastern and western culture, which could possibly prompt misunderstanding into injury case.

\section{THE SUGGESTIONS FOR INTERCULTURAL ADAPTATION OF EXCHANGE STUDENTS IN FOREIGN LANGUAGE UNIVERSITIES}

Intercultural adaptation plays an important role in mental development and personal growth of students. We should attach importance to the cultivation of students' intercultural adaptability and communication ability based on the present problems and influencing factors, combining the aspects of studying, living and mentality when considering the cultivation. In this way can a sound, useful and popularized intercultural ability training model be formed, promoting the 
fast and sustainable development of internationalization of higher education.

\section{A. Enhance Intercultural Communication Training and Improve the Intercultural Communication Ability of Exchange Students}

When it comes to the problems of culture adaptation of exchange students, some scholars come up the idea of "comprehensive training mode in overseas ethnographic style", i.e. , training students in the aspects of foreign language, intercultural theory, Chinese traditional culture and study abroad plan report etc. This training mode aims to provide particular educational management mode, which could improve the adaptability of exchange students. Meanwhile, the universities can combine the courses and after-class lectures to construct various intercultural education systems. Elective language courses and cultural knowledge courses of the target country could be involved in the courses plan. Strengthening the basic language ability by learning these courses can not only greatly help exchange students live and study abroad, but also enrich the intercultural knowledge and communication ability of exchange students. Foreign language universities possess more advantages when facilitating language courses, which can be used to develop language ability of students, driving them to grasp better understanding of cultural knowledge, and promoting the project to run smoothly during the process of learning language. The setting of after-class lectures is mainly based on the sources from alumnus and professors of the countries in exchange projects, offering different kinds of language and culture adaptation lectures and activities. These events could enable exchange students to get closer to local culture and customs of the exchange countries in a more specific way so that they can adapt to the life abroad more easily.

\section{B. Strengthen the Education of Overall Abilities and Develop the Adaptability of Intercultural Values of Exchange Students}

Universities should make full use of course education, social practice and cultural activity, guiding students to follow the core socialist values and foster correct world outlook, view on life and values. On one hand, university needs to select outstanding as well as patriotic students in order to set positive examples, spreading positive influence and guiding students to build up correct world outlook, view on life and values as well as shaping stronger confidence in the path, theory, system and culture. On the other hands, university can integrate professional education, vocational education and individual development into the education of overall abilities by the use of internet. At the same time, the education activities with various different kinds of forms can be also launched. As for selection of exchange students, universities should try very best to select those who can represent Chinese image, hold strong love of motherland as well as being able to spread "Chinese stories" well.

\section{Solidify Safety Education and Improve Intercultural Safety Adaptability of Exchange Students}

The safety education can be carried out in three stages: before, during and after studying abroad, including the education of laws, regulations and health care insurances. The significance of safety education is greatly suggested in the safety incidents which overseas students often encountered.

1) Pay attention to the education before going abroad: Based on intercultural training, universities should offer as much information of target country as possible, such as economic, political and social situation, laws, social customs, cultural features, customs policy and whether exchange students can do part-time jobs or not and so on. In addition, exchange students need to prepare themselves well; especially to learn the legal risks of the country they are going to leave for. Meanwhile, exchange students should consider all problems which might happen and give the copy of relevant identity documents to domestic emergency contact person.

2) Keep in contact with exchange students when studying abroad and launch safety education campaign regularly: Domestic universities should build up regulated contact mechanism, which requires exchange students to call back to notify that they have arrived safely and report their situation once a week. Meanwhile, universities can provide emergency number list easily carried which involves the contact number of Chinese embassy, campus and medical institution etc. Students can go for help with this list when coming across problems, improving safety awareness of exchange students. Besides, exchange students should be demanded to learn local social security and medical condition in time on the condition of insuring personal safety. Assisting exchange students to accept effective safety education not only requires the efforts from universities, but also relies on the assistance of family. The university and family should connect and complement with each other, and family should take more responsibility on values guidance and financial support.

3) Universities can launch a campaign for exchange students to present final report of the exchange projects they joined: They can share the experiences of studying abroad and matters which need to be paid attention to such as local economy, politics and culture in form of paper or group meetings. In the way of effectively communication with junior schoolmates a scientific and sustainable intercultural adaptation mode of exchange students can be formed.

\section{CONCLUSION}

In conclusion, the intercultural adaptation ability of exchange students can be improved in terms of enhancing intercultural communication training, strengthening the education of overall abilities and solidifying safety education. Meanwhile, the intercultural communication ability, adaptability of intercultural value and intercultural safety adaptability should also be well cultivated and developed. 
Then the educational management can be better implemented, promoting the sustainable development of the international communication of universities.

\section{REFERENCES}

[1] Shang D \& Yin Y S \& Zhang X, The Reflection of Educational Management Problems Based on Interviews of Exchange Students, Journal of Hubei Correspondence University, 2018(10), 13-16.

[2] Jin G T \& Liu C \& Cheng Z Y,The Current Situation of Intercultural Communication Ability of University Students and Cultivation Strategy Under "the Belt and Road" Initiatives, Journal of Naval University of Engineering (Comprehensive Edition), 2017(01), 83-87.

[3] Wang Z L,A Survey on Acculturation Students in Universities of Beijing, China Higher Education Research, 2016(01), 91-96.

[4] Su Z Z \& Xie Q S, The Research on Education and Management Mechanism of Exchange Students in Universities: Take Xiamen University of Technology as example, HEILONGJIANG EDUCATION (Higher Education Research \& Appraisal), 2014(10), $71-73$

[5] Tan Y \& Tao Ru Cross-cultural Adaptation Issue if Students under Chinese-foreign Higher Education Cooperation Programs and Its Influencing Factors, Journal f Beifang University of Nationalities, 2014(06), 114-117.

[6] Zou H, Strengthening and Improving the Education of Exchange Students in Universities, Journal of China Youth University of Political Studies, 2012(03), 63-66. 